\title{
Electrocatalytic activity of ligand-protected gold particles: formaldehyde oxidation
}

\author{
Kun Luo $\cdot$ Haiming Wang $\cdot$ Xiaogang Li
}

Published online: 7 October 2013

(C) The Author(s) 2013. This article is published with open access at SpringerLink.com

\begin{abstract}
Tris(hydroxymethyl)phosphine oxide (THPO) and triphenyl phosphine oxide $\left(\mathrm{PPh}_{3} \mathrm{O}\right)$ were introduced onto the surface of colloidal gold nanoparticles (Au NPs), and the effect of capping ligands on the catalytic electrooxidation of formaldehyde was studied voltammetrically by using colloidal Au-NP-modified glassy carbon electrodes (GCEs). This was compared with polycrystalline Au and another Au-NPmodified GCE without a capping molecule. We found that $\mathrm{PPh}_{3} \mathrm{O}$ causes a larger decrease in the catalytic activity of the Au NPs in liquid than THPO does, indicating that the catalytic activity of the Au NPs is closely associated with the capping ligands. The effect of capping ligands is discussed based on the available surface ratio (ASR), which is defined as the ratio of the total surface area measured electrochemically to the calculated value based on the number and geometry of the $\mathrm{Au}$ NPs. These were determined to be $70.6 \%$ for THPO and $0.23 \%$ for $\mathrm{PPh}_{3} \mathrm{O}$, respectively. The significant blocking of formaldehyde is probably due to the structure and hydrophobicity of the benzene rings in the $\mathrm{PPh}_{3} \mathrm{O}$ molecule, which is responsible for the decrease in catalytic activity of the Au NPs.
\end{abstract}

Keywords Gold nanoparticle · Ligand · Catalytic activity · Formaldehyde $\cdot$ Voltammetry

\section{Introduction}

Since the catalytic property of gold nanoparticles (Au NPs) was revealed by Haruta et al. [1] and Hutchings et al. [2], the effect of the particulate size of gold has been extensively

K. Luo $(\bowtie) \cdot$ H. Wang $\cdot$ X. Li

Key Laboratory of New Processing Technology for Nonferrous Metals and Materials, Ministry of Education, College of Materials Science and Engineering, Guilin University of Technology,

Guilin 541004, China

e-mail: luokun@glut.edu.cn investigated [3-7]. Nanoparticles between 2 and $50 \mathrm{~nm}$ have been determined to be heterogeneous catalysts [8-10]. Goldbased catalysts are normally composites of Au NPs and insulating oxide supports, and these catalysts exhibit the best lowtemperature activity for $\mathrm{CO}$ oxidation among all catalysts [11]. Their catalytic activity exceeds the catalytic activity of platinum group metals by a factor of about five [12, 13]. Gold catalysts have also been reported to be uniquely selective for the partial oxidation of propene to propene oxide [4]. However, disagreement on the mechanisms of the catalytic processes remains [8].

The large surface energy of Au NPs makes them prone to aggregation, and capping ligands or macromolecules need to be used to stabilize these colloidal metal systems [14], which normally results in a decrease in catalytic activity of the $\mathrm{Au}$ NPs. Au also undergoes deactivation upon poisoning as a result of chemisorption, as do other noble metal catalysts. For example, chloride is regarded as a potent poison of gold catalysts, which readily adsorbs onto the surface of gold when $\mathrm{HAuCl}_{4}$ is used as a starting material $[8,15]$. Calcination is often employed to remove capping molecules from Au NPs, which leads to the growth of Au particulates. Electrochemical deposition or stripping of $\mathrm{PbO}_{2}$ films offers another route for the removal of organic species on a gold surface $[16,17]$. However, it is not feasible for use with Au-based catalysts because the Au NPs are normally deposited on insulating oxides. It is thus necessary to understand the effect of surface chemistry on the electrocatalytic activity of Au-NP catalysts.

The catalytic activity of noble metals can be studied electrochemically in solutions of strong reducing agents such as hydrazine, borohydride, dimethylamine borane, and formaldehyde. Au was found to be more active in formaldehyde alkaline solutions [18] than in other solutions. Formaldehyde dissolves in water as a weakly acidic gem-diol, which deprotonates in alkaline solutions to form the electroactive enolate anion [19]. The enolate anion is oxidized on gold and 
follows the reported scheme $[20,21]$ to form $\mathrm{HCOO}^{-}$and $\mathrm{CO}_{2}$, and this is accompanied by hydrogen evolution [22]. On platinum and palladium, formaldehyde oxidation occurs without hydrogen generation.

The catalytic activity of Au NPs can be studied using AuNP-modified glassy carbon electrodes (GCEs). The signal-tonoise ratio during electroanalysis is often closely associated with the loading and the surface chemistry of the Au NPs on the modified GCEs. A few methods are available for the preparation of Au-NP-modified GCEs such as electrodeposition [23], the spontaneous reduction of $\mathrm{AuCl}_{4}{ }^{-}$on carbon [24], or the direct adsorption of Au-NP colloids [24]. To increase the Au-NP loading on modified electrodes without serious agglomeration, the self-assembly of Au-NP colloids at immiscible liquid/liquid (L/L) interfaces can also be used [25-30]. A spontaneous interfacial reaction was recently reported by Rao et al. [31, 32] between chloro(triphenylphosphine)gold(I) $\left(\mathrm{Au}\left(\mathrm{PPh}_{3}\right) \mathrm{Cl}\right)$ in toluene and tetrakis(hydroxymethyl)phosphonium chloride (THPC) in an aqueous alkaline solution. This reaction directly generates robust Au-NP ultrathin films at the L/ $\mathrm{L}$ interface. Our previous work [33] indicated that the spontaneous $\mathrm{L} / \mathrm{L}$ interfacial reaction is actually composed of two simultaneous steps: Au particle formation and self-assembly that leads to compositionally similar ultrathin Au-NP films in the interfacial reaction and the self-assembly methods. Organophosphorus molecules that form during the interfacial reaction play an important role in determining the morphology of the interfacial deposit. In this paper, a further voltammetric investigation was performed using Au-NP-modified GCEs in alkaline formaldehyde solutions to study the effect of ligand molecules on the catalytic activity of Au NPs in liquids.

\section{Experimental}

\section{Chemicals}

Formaldehyde $\left(\mathrm{CH}_{2} \mathrm{O}, 36 \%\right.$ in water, Aldrich), sodium tetrachloroaurate (III) dihydrate $\left(\mathrm{NaAuCl}_{4}, 99.99 \%\right.$, Alfa Aesar), tetrakis(hydroxymethyl)phosphonium chloride (THPC, $80 \%$, Aldrich), triphenyl phosphine $\left(\mathrm{PPh}_{3}, 99 \%\right.$, Aldrich), hydrochloric acid ( $\mathrm{HCl}, 37 \%$, Aldrich), nitric acid $\left(\mathrm{HNO}_{3}\right.$, $69 \%, \mathrm{BDH})$, and phosphate buffer solution $(\mathrm{pH}=7.32$, Fisher Scientific) were used as received.

Preparation of the Au colloid

A total of $165 \mu \mathrm{l}$ of $50 \mathrm{mM}$ THPC solution was injected into $8 \mathrm{ml}$ of $6.25 \mathrm{mM} \mathrm{NaOH}$ solution. After stirring for $5 \mathrm{~min}, 3 \mathrm{ml}$ of a $3.3-\mathrm{mM} \mathrm{NaAuCl}_{4}$ solution was added dropwise, and this is a variant of the approach described by Duff et al. [34]. The appearance of a dark red solution indicated the formation of an Au colloid.

Modification of glassy carbon electrodes

Glassy carbon electrodes (GCEs, $3 \mathrm{~mm}$ diameter, $\mathrm{CH}$ Instruments Inc.) were employed as catalytically inert substrates. The GCEs were carefully polished with diamond spray $(0.1 \mu \mathrm{m}$, Kemet International Ltd. $)$ and sonicated in deionized water before use.

Modification 1 A total of $5 \mathrm{ml}$ of the as-prepared Au colloid was mixed and shaken vigorously with $5 \mathrm{ml}$ of pure toluene as described by Binks et al. [25] where the resultant interfacial deposit was transferred onto a clean GCE leading to a modified electrode designated "GCEAuTHPO" after drying in air.

Modification 2 A total of $5 \mathrm{ml}$ of the as-prepared Au colloid was mixed with $5 \mathrm{ml}$ of a $5-\mathrm{mM} \mathrm{PPh}_{3}$ toluene solution. After vigorous shaking, a deposit was formed at the toluene/water interface, which was transferred onto a clean GCE, and a modified electrode designated "GCE-AuPPhO" was prepared after drying in air.

Modification 3 A clean GCE was immersed in a 3.3-mM $\mathrm{NaAuCl}_{4}$ solution for $5 \mathrm{~min}$, and a modified electrode designated "GCE-AuCl" was prepared by the spontaneous interaction between $\mathrm{AuCl}_{4}^{-}$and carbon as suggested by Vaskelis et al. [22].

All the modified GCEs were rinsed with deionized water before use. Transmission electron microscopy (TEM) was carried out to characterize the Au NPs on the modified GCEs with a Tecnai F30 FEG-TEM system operating at $300 \mathrm{kV}$.

\section{Electrochemistry}

A three-electrode system under the control of a PGSTAT30 Potentiostat (Autolab, Eco Chemie B.V.) was used. A platinum mesh and a silver/silver chloride wire $(\mathrm{Ag} / \mathrm{AgCl} / 3 \mathrm{M}$ $\mathrm{KCl}$ ) were used as counter and reference electrodes, respectively. The working electrodes were gold polycrystalline discs, unmodified GCE, and the modified GCEs described above. All the alkaline formaldehyde solutions were freshly prepared and were degassed in pure argon before commencing voltammetry. The amount of Au NPs on the modified GCEs was determined by anodic stripping in a dilute aqua regia solution [35] containing $0.1 \mathrm{M} \mathrm{HCl}$ and $0.32 \mathrm{M} \mathrm{HNO}_{3}$ (in a molar ratio of roughly 1:3). Linear sweep voltammetry was 
carried out from 0 to $1.4 \mathrm{~V}$ (vs. $\mathrm{Ag} / \mathrm{AgCl}$ ) repeatedly until the stripping peaks were invisible. The sum of the serial oxidation peaks was taken to correspond to the amount of Au deposited as per Faraday's laws. The total available surface area of the $\mathrm{Au}$ NPs on the modified GCEs was measured by the ratio of the reduction peak area to a value of $482 \mu \mathrm{C} / \mathrm{cm}^{2}$ in a phosphate buffer solution ( $\mathrm{pH}$ 7.32), according to the method of Hoogvliet and Oesch $[35,36]$. The potentials in the figures are quoted versus the $\mathrm{Ag} / \mathrm{AgCl}$ reference electrode.

\section{Results and discussion}

Electrocatalytic oxidation of formaldehyde

Figure 1 compares cyclic voltammetry (CV) curves of the polycrystalline Au electrode, the unmodified GCE, and the Au-NP-modified GCEs. In Fig. 1a, the catalytic electrooxidation of $\mathrm{CH}_{2} \mathrm{O}$ on the bulk $\mathrm{Au}$ electrode generates two oxidation peaks at ca. -0.27 and $+0.68 \mathrm{~V}$ (vs. Ag/ $\mathrm{AgCl}$ ) in a solution containing $0.1 \mathrm{M} \mathrm{CH}_{2} \mathrm{O}$ and $0.1 \mathrm{M}$ $\mathrm{KOH}$ (solid). These peaks are not visible in the absence of $\mathrm{CH}_{2} \mathrm{O}$ in the alkaline solution (dotted). This result is in agreement with previous literature [20]. In contrast, there is only one peak present in the voltammograms of the AuNP-modified GCEs where the curve of the bare GCEs

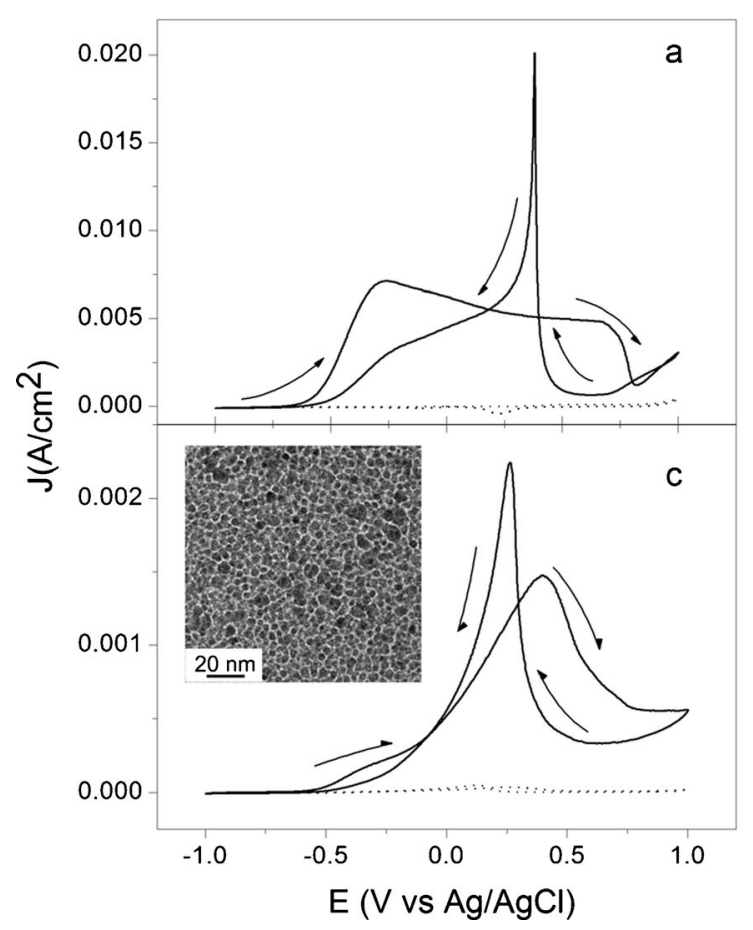

Fig. 1 Cyclic voltammograms of unmodified GCE (dotted line) in a 0.1$\mathrm{M} \mathrm{CH}_{2} \mathrm{O}$ and $0.1-\mathrm{M} \mathrm{KOH}$ solution at a potential scan rate of $50 \mathrm{mV} \mathrm{s}^{-1}$ for $a$, gold electrode; $b$, GCE-AuCl; $c$, GCE-AuTHPO; and $d$, GCE- appears to be catalytically inert toward the reaction (dotted lines in Fig. 1b-d). This is indicative of the strong catalytic activity of the $\mathrm{Au}$ NPs toward the anodic oxidation of formaldehyde. The decrease in the peak at $-0.27 \mathrm{~V}$ in Fig. 1b-d implies that the anodic oxidation of formaldehyde on Au NPs follows a different pathway compared with bulk Au. According to Yang et al. [37], the electrooxidation of formaldehyde on Au-NP-modified GCEs produces $\mathrm{HCOO}^{-}$because of GCE substrate restrictions while the reaction on bulk $\mathrm{Au}$ normally generates $\mathrm{CO}_{2}$ instead of $\mathrm{HCOO}^{-}$, which also highlights the product selectivity characteristic of Au-based nanocatalysts. The mechanistic difference was thus examined again and verified by the results in Fig. 1.

The peak potentials in Fig. 1b-d were also found to vary with surface molecules and were around $+0.35 \mathrm{~V}$ for GCE$\mathrm{AuCl},+0.40 \mathrm{~V}$ for GCE-AuTHPO, and $+0.50 \mathrm{~V}$ for GCEAuPPhO. The order is thus: GCE-AuCl $<$ GCE-AuTHPO $<$ GCE-AuPPhO. However, the peak current density based on the geometry of the supporting GCEs has a different sequence as the values are $0.0047,0.0016$, and $0.0022 \mathrm{~A} \mathrm{~cm}^{-2}$ for GCE$\mathrm{AuCl}$, GCE-AuTHPO, and GCE-AuPPhO, respectively. This order is thus: GCE-AuCl $<$ GCE-AuPPhO $<$ GCE-AuTHPO. To understand this phenomenon, the effects of morphology and capping ligand molecules of the Au NPs on the catalytic property have to be further investigated.

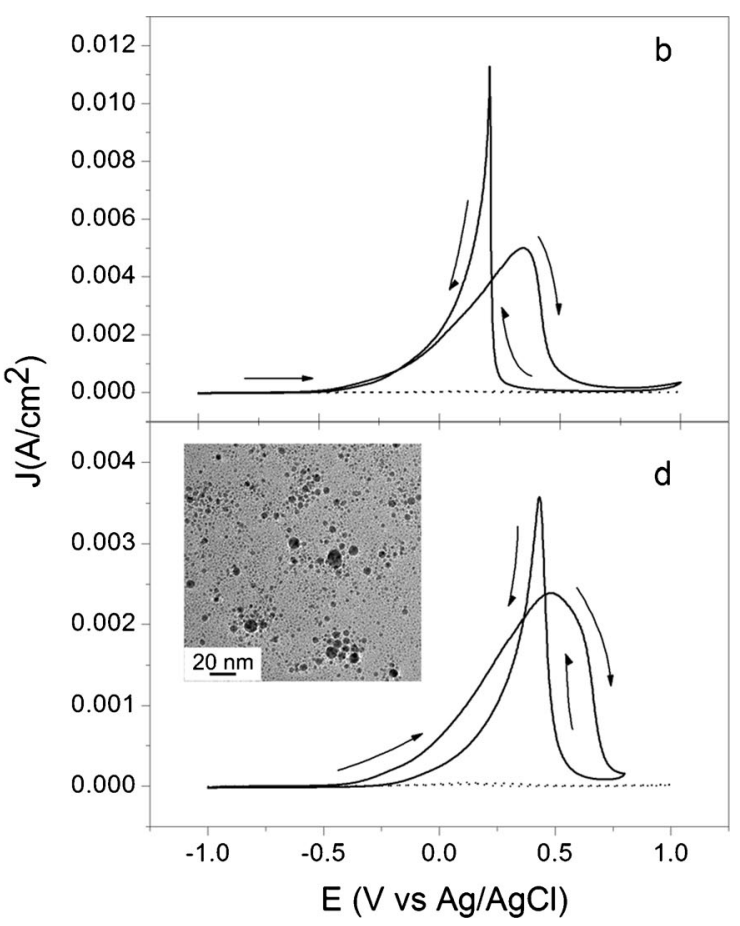

AuPPhO. The third scans for each electrode were obtained for comparison. Insets are the TEM images of the Au NPs on GCE-AuTHPO and GCE-AuPPhO, respectively 
Morphology of the Au NPs

TEM micrographs of the Au NPs on the modified GCEs are shown in the insets of Fig. 1c, d. The average diameters were measured to be $2.1 \pm 0.7 \mathrm{~nm}(N=544)$ for GCE-AuTHPO and $2.6 \pm 1.5 \mathrm{~nm}(N=331)$ for GCE-AuPPhO, which is indicative of the similar sizes of the two Au deposits. We have previously determined the nature of the functional groups on the two AuNP deposits by XPS analysis [33]. These included tris(hydroxymethyl)phosphine oxide (THPO) for GCEAuTHPO and tri(phenyl)phosphine oxide $\left(\mathrm{PPh}_{3} \mathrm{O}\right)$ plus THPO for GCE-AuPPhO. THPO is the cleavage product of THPC in alkaline solution, and it adsorbs onto the surface of the colloidal $\mathrm{Au}$ NPs as a protecting ligand during the reduction of $\mathrm{NaAuCl}_{4}$. The THPO-functionalized Au-NP colloid undergoes self-assembly when it is in contact with pure toluene leading to GCE-AuTHPO without agglomerated Au NPs. When $\mathrm{PPh}_{3}$ is present in toluene, a competitive ligand exchange process probably occurs between THPO and $\mathrm{PPh}_{3}$. Most THPO is replaced by $\mathrm{PPh}_{3} \mathrm{O}\left(\mathrm{PPh}_{3}\right.$ can be converted into $\mathrm{PPh}_{3} \mathrm{O}$ in a basic environment) although a small amount of THPO still remains. For GCE-AuCl deposition, previous reports on the catalytic oxidation of formaldehyde and stripping experiments $[24,38]$ have indicated the presence of metallic $\mathrm{Au}$ NPs on the GCE surface because of the spontaneous interaction between $\mathrm{AuCl}_{4}{ }^{-}$and carbon. A similar reduction of silver ions by carbon has also been described previously [38]; however, to date, no morphological evidence has been available to support these conclusions. In our experiments, we attempted to find Au particles in the TEM images, but only a few Au NPs were available for measurement on the GCE$\mathrm{AuCl}$ possibly because of the limited loading of Au. However, deductions can still be made through voltammetric investigations.

The amount of $\mathrm{Au}$ that deposited on the GCE-AuCl, GCEAuTHPO, and GCE-AuPPhO electrodes was determined by anodic stripping, where linear sweep voltammetry was repeated from 0 to $1.4 \mathrm{~V}$ in a mixed acid solution $(0.1 \mathrm{M} \mathrm{HCl}$ and $0.32 \mathrm{M} \mathrm{HNO}_{3}$ ) at a scan rate of $200 \mathrm{mV} \mathrm{s}^{-1}$ until the $\mathrm{Au}$ stripping peak was invisible. Additionally, all the stripping peaks were at ca. $1.1 \mathrm{~V}$ (not shown). The sum of the serial oxidation peaks corresponds to the amount of $\mathrm{Au}$ deposited according to Faraday's laws:

$m=Q M_{\mathrm{Au}} / z F$,

where $Q$ is the sum of the measured charge of the stripping peaks, $M_{\mathrm{Au}}$ is the atomic mass of gold, $z$ is the charge transferred per $\mathrm{Au}$ atom (taken as 3 for the stripping process), and $F$ is the Faraday constant. The mass of Au NPs on the modified GCE was then calculated separately using Eq. 1, giving $0.15,11.2$, and $1,150 \mathrm{ng}$ for the GCE-AuCl, GCEAuTHPO, and GCE-AuPPhO, respectively. The loading of the $\mathrm{GCE}-\mathrm{AuCl}$ is much smaller than that reported previously [24], possibly because of the weaker interaction between $\mathrm{AuCl}_{4}{ }^{-}$and carbon in basic solutions compared with low-pH solutions. The current density values based on the loading of $\mathrm{Au}$ NPs for the electrooxidation of formaldehyde in Fig. 1 were calculated to be $3.3 \times 10^{7}, 1.00 \times 10^{5}$, and $2.0 \times 10^{3} \mathrm{~A} \mathrm{~g}^{-1}$ for GCE-AuCl, GCE-AuTHPO, and GCE-AuPPhO, respectively, which is in agreement with the sequence of peak potentials shown in Fig. 1. Therefore, both the thermodynamic and kinetic data suggest that the presence of organophosphorus ligand molecules tends to decrease the catalytic activity of $\mathrm{Au}$ NPs toward the electrooxidation of formaldehyde where $\mathrm{PPh}_{3} \mathrm{O}$ exhibits more influence than THPO. A further discussion about the available surface area of the Au NPs may help to determine the reason for $\mathrm{PPh}_{3} \mathrm{O}$ being better at blocking formaldehyde than THPO.

\section{Effect of ligand molecules}

The effect of organophosphorus molecules on the catalytic activity of the Au NPs on the modified GCEs can be determined by the available surface ratio (ASR), which is defined as the ratio of the measured total surface area to the calculated area based on the number and geometry of Au NPs. Assuming that the Au NPs are spherical, the available surface ratio can be expressed as follows:

$\mathrm{ASR}=\frac{S_{m}}{S}=\frac{S_{m}}{N \pi d^{2}}$,

where ASR represents the available surface ratio, and $S_{m}, N$, and $d$ are the measured total surface area, particle number, and diameter of the Au NPs, respectively. The total mass $(m)$ and surface area $(s)$ based on the geometry of the Au NPs can be expressed as follows:

$m=N \rho_{\mathrm{Au}} V=\frac{1}{6} N \pi d^{3} \rho_{\mathrm{Au}}$,

$S=N \pi d^{2}$

where $V$ and $\rho_{\mathrm{Au}}$ are the particle volume and density of the $\mathrm{Au}$ NPs (19.3 g/ $\mathrm{cm}^{3}$ [39]). From Eqs. 3 and 4, the diameter $(d)$ and particulate number $(N)$ of the Au NPs can be written as:

$d=\frac{6 m}{S \rho_{\mathrm{Au}}}$,

$N=\frac{S}{\pi d^{2}}$.

The above equations suggest that $S_{m}$ can be different from $S$ when a part of the Au surface is covered by capping ligands and the available ratio of the surface can be estimated once the number and size of the Au NPs have been determined. For the 
Fig. 2 Cyclic voltammograms of the bare and the Au-NP-modified GCEs in a phosphate buffer solution $(\mathrm{pH}=7.32)$ at a potential scan rate of $50 \mathrm{mV} \mathrm{s}^{-1}$. The first scans were used. The inset displays the cathodic scan of the GCE-AuCl against the bare GCE

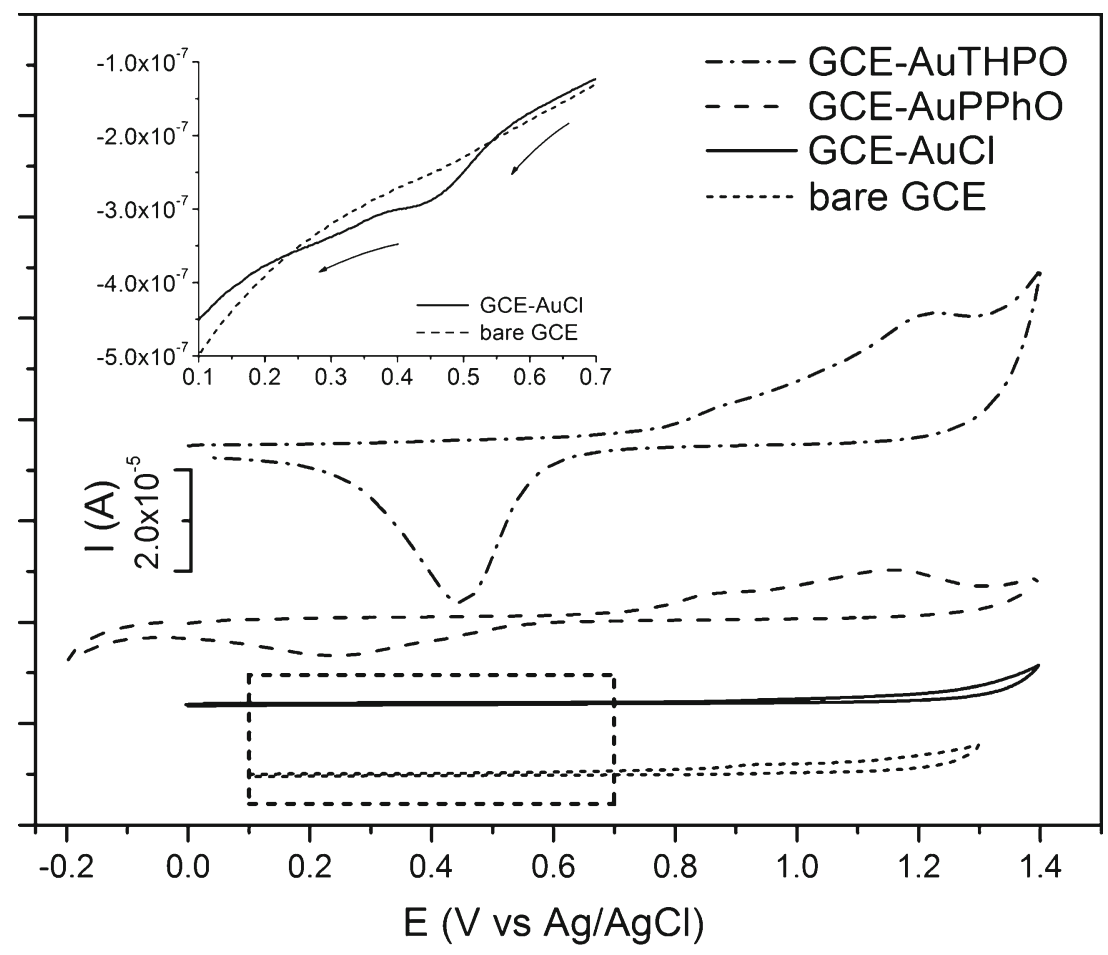

$\mathrm{GCE}-\mathrm{AuCl}$, it can be assumed that the whole surface of the $\mathrm{Au}$ NPs is available (ASR $=100 \%$ ) or that the whole area is not affected by the possible adsorption of chloride. Therefore, the diameter of the Au NPs can be estimated directly from stripping and surface area measurements.

The total mass of the Au NPs can be calculated from the anodic stripping experiment, and the total available surface area can be measured voltammetrically in $\mathrm{pH} 7.32$ phosphate buffer solution $[35,36]$. During the CV experiments, the oxidation peaks for the GCE-AuTHPO and GCE-AuPPhO were found to decay with successive scans, which recovered when the experiments were restarted (not shown). This implies that the available surface of the Au-NP assemblies varied with the consumption of analyte. In contrast, such a decrease was not noticeable for $\mathrm{GCE}-\mathrm{AuCl}$ possibly because of the low loading and the dispersive state of the Au NPs. Therefore, the first scans of the modified GCEs at a scan rate of $50 \mathrm{mV} \mathrm{s}^{-1}$ were used to estimate the total surface area of the Au NPs as shown in Fig. 2. GCE-AuTHPO gave the largest reduction peak, and GCE-AuPPhO gave the second largest peak with a negative shift. The reductive shoulder for $\mathrm{GCE}-\mathrm{AuCl}$ only becomes visible when the curve is compared against the unmodified GCE (shown in the inset). Based on the assumption that a monolayer of chemisorbed oxygen with a gold/ oxygen ratio of 1:1 was formed, the total available surface area can be calculated from the ratio of the reduction peak area to a previously reported factor of $482 \mu \mathrm{C} / \mathrm{cm}^{2}$, which corresponds to the reduction charge of chemisorbed oxygen according to Hoogvliet and Oesch $[35,36]$. We thus obtained values of $1.8 \times 10^{-5}, 1.2 \times 10^{-2}$, and $3.1 \times 10^{-3} \mathrm{~cm}^{2}$ for $\mathrm{GCE}-\mathrm{AuCl}$, GCE-AuTHPO, and GCE-AuPPhO, respectively.

Combining the results from the stripping and surface area measurements, the average diameter of the Au deposits on GCE-AuCl was calculated to be $26 \mathrm{~nm}$. Using the diameter values of the Au deposits on the modified GCEs, the particle numbers can be estimated by Eq. 6, which gives $8.5 \times 10^{8}$, $1.2 \times 10^{11}$, and $6.5 \times 10^{12}$ for GCE-AuCl, GCE-AuTHPO, and GCE-AuPPhO, respectively. The ASR values for GCE-
Table 1 Values measured and calculated from voltammetric experiments

${ }^{\text {a }}$ Assuming that the absorption of chloride does not affect the available surface for the electrooxidation of formaldehyde

\begin{tabular}{llll}
\hline Items & GCE-AuCl & GCE-AuTHPO & GCE-AuPPhO \\
\hline Oxidation peak potential (V) & 0.35 & 0.40 & 0.50 \\
Oxidation peak current density (A/g) & $2.2 \times 10^{6}$ & $1.0 \times 10^{4}$ & $1.4 \times 10^{2}$ \\
Measured area $\left(\mathrm{cm}^{2}\right)$ & $1.8 \times 10^{-5}$ & $1.2 \times 10^{-2}$ & $3.1 \times 10^{-3}$ \\
Amount of Au NPs (ng) & 0.15 & 11.2 & 1,150 \\
Particle number & $8.5 \times 10^{8}$ & $1.2 \times 10^{11}$ & $6.5 \times 10^{12}$ \\
Available surface ratio (ASR) & $100 \%{ }^{\mathrm{a}}$ & $70.6 \%$ & $0.23 \%$ \\
\hline
\end{tabular}


AuTHPO and GCE-AuPPhO were determined using Eq. 2 to be 70.6 and $0.23 \%$, respectively.

All the above values were measured and calculated from voltammetric experiments and the TEM images, and the data are listed in Table 1, which show that the adsorption of organophosphorus molecules obviously decreases the catalytic activity of the Au NPs. The benzene rings in the $\mathrm{PPh}_{3} \mathrm{O}$ molecule occupy a larger space and appear more hydrophobic than THPO, which is probably responsible for the much larger obstruction to the transfer of formaldehyde to the surface of the Au NPs. This would, therefore, lead to a very small ratio of available surface area. This highlights the necessity of balancing the activity of Au-NP-based catalysts and the protection of $\mathrm{Au}$ NPs from aggregation.

\section{Conclusion}

The effect of capping ligands THPO and $\mathrm{PPh}_{3} \mathrm{O}$ on the catalytic activity of Au NPs was studied voltammetrically using Au-NP-modified GCEs and compared with polycrystalline $\mathrm{Au}$ and another Au-NP-modified GCE without a capping molecule. The results reveal that $\mathrm{PPh}_{3} \mathrm{O}$ causes more degradation in the catalytic activity of the Au NPs toward the electrooxidation of formaldehyde compared with THPO, probably because of the structure and hydrophobicity of the benzene rings in $\mathrm{PPh}_{3} \mathrm{O}$. To investigate this effect, the ASR was determined, and we found values of $70.6 \%$ for THPO and $0.23 \%$ for $\mathrm{PPh}_{3} \mathrm{O}$, indicating the significance of these values in describing the degree of obstruction generated by capping ligands toward analytes. This highlights the interplay between the functionalization and stabilization of Au-NPbased catalysts.

Acknowledgments We thank the National Natural Science Foundation of China (grant no. 21163004) and Guangxi Natural Science Foundation (grant no. 2013GXNSFAA019029). We also sincerely appreciate the academic guidance from Prof. Robert A. W. Dryfe in the University of Manchester.

Open Access This article is distributed under the terms of the Creative Commons Attribution License which permits any use, distribution, and reproduction in any medium, provided the original author(s) and the source are credited.

\section{References}

1. Haruta M, Kobayashi T, Sano H, Yamada N (1987) Chem Lett 16: 405-408

2. Hutchings GJ (1985) J Catal 96:292-295

3. Bond GC (2001) Gold Bull 34:117-140

4. Thompson D (1999) Gold Bull 32:12-19
5. Valden M, Lai X, Goodman DW (1998) Science 281:1647-1650

6. Salisbury BE, Wallace WT, Whetten RL (2000) Chem Phys 262: 131-141

7. Prati L, Martra G (1999) Gold Bull 32:96-101

8. Cortie MB, Lingen E (2002) Materials Forum 26:1-14

9. Hughes MD, Xu Y-J, Jenkins P, McMorn P, Landon P, Enache DI, Carley AF, Attard GA, Hutchings GJ, King F, Stitt EH, Johnston P, Griffin K, Kiely CJ (2005) Nature 437:1132-1135

10. Schubert MM, Hackenberg S, van Veen AC, Muhler M, Plzak V, Behm RJ (2001) J Catal 197:113-122

11. Grisel R, Weststrate KJ, Gluhoi A, Nieuwenhuys BE (2002) Gold Bull 35:39-45

12. Thompson D (1998) Gold Bull 31:111-118

13. Bond GC, Thompson DT (2000) Gold Bull 33:41-51

14. Porta F, Prati L, Rossi M, Coluccia S, Martra G (2000) Catal Today 61:165-172

15. Yuan YZ, Kozlova AP, Asakura K, Wan HL, Tsai K, Iwasawa Y (1997) J Catal 170:191-199

16. Hernandez J, Solla-Gullon J, Herrero E (2004) J Electroanal Chem 574:185-196

17. Hernandez J, Solla-Gullon J, Herrero E, Aldaz A, Feliu JM (2006) Electrochim Acta 52:1662-1669

18. Yahikozawa K, Nishimura K, Kumazawa M, Tateishi N, Takasu Y, Yasuda K, Matsuda Y (1992) Electrochim Acta 37:453-455

19. ten Kortenaar MV, Tessont C, Kolar ZI, van der Weijde H (1999) J Electrochem Soc 146:2146-2155

20. ten Kortenaar MV, Kolar ZI, de Goeij JJM, Frens G (2002) Langmuir 18:10279-10291

21. ten Kortenaar MV, Kolar ZI, de Gopeij JJM, Frens G (2001) J Electrochem Soc 148:E327-E335

22. Bindra P, Roldan JM, Arbach GV (1984) Ibm J Res Dev 28:679-689

23. El-Deab MS, Okajima T, Ohsaka T (2003) J Electrochem Soc 150: A851-A857

24. Vaskelis A, Tarozaite R, Jagminiene A, Tamasiunaite LT, Juskenas R, Kurtinaitiene M (2007) Electrochim Acta 53:407-416

25. Binks BP, Clint JH, Fletcher PDI, Lees TJG, Taylor P (2006) Langmuir 22:4100-4103

26. Wang DY, Duan HW, Mohwald H (2005) Soft Matter 1:412-416

27. Duan HW, Wang DA, Kurth DG, Mohwald H (2004) Angewandte Chemie-Int Ed 43:5639-5642

28. Reincke F, Kegel WK, Zhang H, Nolte M, Wang DY, Vanmaekelbergh D, Mohwald H (2006) Phys Chem Chem Phys 8: 3828-3835

29. Reincke F, Hickey SG, Kegel WK, Vanmaekelbergh D (2004) Angewandte Chemie-Int Ed 43:458-462

30. Shen Z, Yamada M, Miyake M (2007) J Am Chem Soc 129:1427114280

31. Rao CNR, Kulkarni GU, Agrawal VV, Gautam UK, Ghosh M, Tumkurkar U (2005) J Colloid Interface Sci 289:305-318

32. Rao CNR, Kulkarni GU, Thomas PJ, Agrawal VV, Saravanan P (2003) J Phys Chem B 107:7391-7395

33. Luo K, Schroeder SLM, Dryfe RAW (2009) Chem Mater 21:41724183

34. Duff DG, Baiker A, Edwards PP (1993) J Chem Soc Chem Comm 1: 96-98

35. Hoogvliet JC, Dijksma M, Kamp B, van Bennekom WP (2000) Anal Chem 72:2016-2021

36. Oesch U, Janata J (1983) Electrochim Acta 28:1237-1246

37. Yang H, Lu T, Xue K, Sun S, Lu G, Chen S (1999) J Mol Catal A Chem 144:315-321

38. Ragoisha GA, Jovanovic VM, Avramovivic MA, Atanasoski RT, Smyrl WH (1991) J Electroanal Chem 319:373-379

39. Hotta H, Ichikawa S, Sugihara T, Osakai T (2003) J Phys Chem B 107:9717-9725 